\title{
Targeting breast cancer stem cells: fishing season open!
}

\author{
Christophe Ginestier*, Emmanuelle Charafe-Jauffret and Daniel Birnbaum
}

\begin{abstract}
Studies describing the tumor as a hierarchically organized cell population have changed the classical

oncogenesis view and propose new therapeutic strategies. Cancer stem cells (CSCs) are thought to sustain tumor initiation/maintenance, therapy resistance, and systemic metastases. Targeting this tumor cell population is crucial to achieve a true cancer cure. A large research effort is now aiming to develop drugs targeting CSCs, based either on a priori understanding of key pathways regulating CSC biology or on high-throughput screening to identify novel targets and compounds.
\end{abstract}

\section{Background}

In recent years, tumor-initiating cells - so-called cancer stem cells (CSCs) - have been characterized in multiple cancers, including breast cancer [1]. This component of cancer cells retains key stem cell properties, including selfrenewal (which initiates and drives tumorigenesis) and differentiation, albeit aberrant (which contributes to cellular heterogeneity). Moreover, CSCs are thought to be the seed for the distant metastasis responsible for poor clinical outcome $[2,3]$. The discovery of CSCs provides an explanation for why cancer may be so difficult to cure, and suggests new therapeutic strategies. Several studies demonstrate that breast CSCs are resistant to conventional therapeutic strategies such as radiotherapy or chemotherapy [2]. Neoadjuvant chemotherapy thus leads to an increase in breast CD24-/CD44 $4^{+}$or $\mathrm{ALDH}^{\text {high }} \mathrm{CSCs}$ and tumorsphere-initiating cells $[4,5]$. If these cells are the tumor root, then they are the cells to be killed.

Two approaches have been developed to design the best therapeutic strategies targeting CSCs. The first

*Correspondence: christophe.ginestier@inserm.fr

Centre de Recherche en Cancérologie de Marseille, Laboratoire d'Oncologie

Moléculaire, UMR891 Inserm/Institut Paoli-Calmettes, 27, Bd Lei Roure, BP 30059 , 13273 Marseille CEDEX 09, France approach is based on targeting key pathways regulating CSC survival, differentiation, and self-renewal. Several master pathways (Hedgehog, NOTCH, and AKT/WNT/ $\beta$-catenin signaling) commonly involved in self-renewal of embryonic and adult stem cells are known to be deregulated in CSCs and to induce an expansion of this population [6]. A number of agents targeting these pathways are currently being tested preclinically, and some have entered clinical trials. Meanwhile, studies of CSCenriched populations using omics technologies are rapidly defining additional regulatory pathways and networks regulating CSC biology. We recently established a gene expression signature that allowed the identification of CXCR1/IL-8 signaling as a key regulator pathway of breast CSC biology [7]. Utilizing a small molecule inhibitor of CXCR1, repertaxin, we were able to specifically target the CSC population in human breast cancer xenografts, retarding tumor growth and reducing metastasis [8].

\section{The article}

To identify novel drugs that target specifically CSCs, researchers from Ciliberto's group have privileged the second approach based on unbiased high-throughput screening (HTS) of small-molecule libraries on CSCenriched populations [9]. Because a tumor cell population could contain very few CSCs, HTS needs to be redesigned to specifically measure gene inhibition or drug effects on the CSC population.

In the MCF7 breast cancer cell line, the authors described a cell population staining pale toluidine blue (light cells) enriched in CSCs. Light cells presented an increase in tumorsphere-forming efficiency and were enriched for ALDH ${ }^{\text {bright }}$ cells, described to exclusively contain the CSC population [7]. When transplanted in immunodeficient mice, light cells were highly tumorigenic compared with bulk MCF7 cells. Utilizing this experimental system, Cioce and colleagues performed a drug-screen assay. A total of 26 compounds were screened for their ability to kill specifically the light cells at a greater rate than the bulk MCF7 cells. The screening assay identified four such compounds, which all interfered with NF-kB signaling [9]. 


\section{The viewpoint}

This unbiased drug-screen strategy on a CSC-enriched population was initially developed in the laboratories of Weinberg and Lander. The model involved experimentally transformed HMLER breast cancer cells modified by shRNA-mediated inhibition of the human E-cadherin gene. Inhibition of E-cadherin expression induced an epithelial-mesenchymal transition, resulting in an increase in $\mathrm{CD} 44^{\text {high }} / \mathrm{CD} 24^{\text {low }}$ cancer cells. A total of 32 compounds in a library of 16,000 chemicals had selective toxicity for these artificially enriched breast CSCs. Among these compounds, salinomycin was the most potent. The use of this potassium ionophore inhibitor as a potential cancer drug is novel and was validated in vivo using breast cancer cell line xenografts, with a decrease in tumor growth and metastasis formation [10].

A similar approach has been developed for human brain tumors with the establishment of several glioma neural stem cell lines stably enriched in CSCs. Utilizing a cell imaging-based chemical screen (comprising 450 US Food and Drug Administration-approved drugs), Dirks' group identified both differential sensitivities of CSCs and a common susceptibility to perturbation of serotonin signaling [11]. These observation suggests that CSCs might be highly susceptible to metabolic changes and may open new therapeutic possibilities.

Other than testing selective drug toxicity on an enriched-CSC population compared with bulk cancer cells, HTS can be designed to directly measure the drug effect on CSC function. Exploiting the relationship between neural stem cell self-renewal and neurosphere proliferation, a screen of more than 1,200 compounds identified several neuromodulators as key regulators of stem cell biology [12]. A similar approach may be envisaged with tumorspheres from breast cancer cell lines.

Instead of using chemicals, RNA interference libraries can be screened to identify factors that control CSC tumorigenicity and stimulate the development of novel anti-CSC therapies. A recent kinome-wide RNA interference screen identified factors that control the balance between maintenance and differentiation of glioblastoma CSCs. For example, silencing of TRRAP was described to increase differentiation of glioblastoma CSCs in vitro and also suppressed tumor formation in vivo [13].

In conclusion, HTS assays of CSCs provide opportunities to identify multiple compounds that could represent new revolutionary therapies. Because these novel compounds will be selected in vitro, it is crucial to extensively validate in vivo the selective toxicity of these drugs toward CSCs, utilizing primary tumor xenografts as a preclinical step. Moreover, serial transplantation of the residual cells isolated from treated tumors will be needed to prove the complete eradication of the tumorinitiating cell population. If the fishing season is officially open, the question remains how to choose the best bait. Developing therapeutic strategies to target CSCs will hence need a thorough and rigorous effort as many challenges remain to be overcome, such as the evaluation of drug efficiency in cancer patients [14].

\section{Abbreviations}

CSC, cancer stem cell; HTS, high-throughput screening; IL, interleukin; NF, nuclear factor; shRNA, short-hairpin RNA.

\section{Competing interests}

The authors declare that they have no competing interests.

\section{Published: 21 September 2010}

\section{References}

1. Visvader JE, Lindeman GJ: Cancer stem cells in solid tumours: accumulating evidence and unresolved questions. Nat Rev Cancer 2008, 8:755-768.

2. Charafe-Jauffret E, Monville F, Ginestier C, Dontu G, Birnbaum D, Wicha MS: Cancer stem cells in breast: current opinion and future challenges. Pathobiology 2008, 75:75-84.

3. Charafe-Jauffret E, Ginestier C, lovino F, Tarpin C, Diebel M, Esterni B, Houvenaeghel G, Extra JM, Bertucci F, Jacquemier J, Xerri L, Dontu G, Stassi G, Xiao Y, Barsky SH, Birnbaum D, Viens P, Wicha MS: Aldehyde dehydrogenase 1-positive cancer stem cells mediate metastasis and poor clinical outcome in inflammatory breast cancer. Clin Cancer Res 2010, 16:45-55.

4. Li X, Lewis MT, Huang J, Gutierrez C, Osborne CK, Wu MF, Hilsenbeck SG, Pavlick A, Zhang X, Chamness GC, Wong H, Rosen J, Chang JC: Intrinsic resistance of tumorigenic breast cancer cells to chemotherapy. J Nat/ Cancer Inst 2008, 100:672-679.

5. Tanei T, Morimoto K, Shimazu K, Kim SJ, Tanji Y, Taguchi T, Tamaki Y, Noguchi S: Association of breast cancer stem cells identified by aldehyde dehydrogenase 1 expression with resistance to sequential Paclitaxel and epirubicin-based chemotherapy for breast cancers. Clin Cancer Res 2009, 15:4234-4241.

6. Liu S, Wicha MS: Targeting breast cancer stem cells. J Clin Oncol 2010, 28:4006-4012.

7. Charafe-Jauffret $E$, Ginestier C, lovino F, Wicinski J, Cervera N, Finetti P, Hur MH, Diebel ME, Monville F, Dutcher J, Brown M, Viens P, Xerri L, Bertucci F, Stassi G, Dontu G, Birnbaum D, Wicha MS: Breast cancer cell lines contain functional cancer stem cells with metastatic capacity and a distinct molecular signature. Cancer Res 2009, 69:1302-1313.

8. Ginestier C, Liu S, Diebel ME, Korkaya H, Luo M, Brown M, Wicinski J, Cabaud O, Charafe-Jauffret E, Birnbaum D, Guan JL, Dontu G, Wicha MS: CXCR1 blockade selectively targets human breast cancer stem cells in vitro and in xenografts. J Clin Invest 2010, 120:485-497.

9. Cioce M, Gherardi S, Viglietto G, Strano S, Blandino G, Muti P, Ciliberto G: Mammosphere-forming cells from breast cancer cell lines as a tool for the identification of CSC-like- and early progenitor-targeting drugs. Cell Cycle 2010, 9:2878-2887.

10. Gupta PB, Onder TT, Jiang G, Tao K, Kuperwasser C, Weinberg RA, Lander ES: Identification of selective inhibitors of cancer stem cells by high-throughput screening. Cell 2009, 138:645-659.

11. Pollard SM, Yoshikawa K, Clarke ID, Danovi D, Stricker S, Russell R, Bayani J, Head R, Lee M, Bernstein M, Squire JA, Smith A, Dirks P: Glioma stem cell lines expanded in adherent culture have tumor-specific phenotypes and are suitable for chemical and genetic screens. Cell Stem Cell 2009, 4:568-580.

12. Diamandis P, Wildenhain J, Clarke ID, Sacher AG, Graham J, Bellows DS, Ling EK, Ward RJ, Jamieson LG, Tyers M, Dirks PB: Chemical genetics reveals a complex functional ground state of neural stem cells. Nat Chem Biol 2007, 3:268-273.

13. Wurdak H, Zhu S, Romero A, Lorger M, Watson J, Chiang CY, Zhang J, Natu VS, Lairson LL, Walker JR, Trussell CM, Harsh GR, Vogel H, Felding-Habermann B, Orth AP, Miraglia $L$, Rines DR, Skirboll SL, Schultz PG: An RNAi screen identifies TRRAP as a regulator of brain tumor-initiating cell differentiation. Cell Stem Cell 2010, 6:37-47.

14. Wang JC: Evaluating therapeutic efficacy against cancer stem cells: new challenges posed by a new paradigm. Cell Stem Cell 2007, 1:497-501.

doi:10.1186/bcr2636

Cite this article as: Ginestier C, et al:: Targeting breast cancer stem cells: fishing season open! Breast Cancer Research 2010, 12:312. 